\section{Mr. H. O. Forbes's Discoveries in the Chatham Islands.}

REFERRING to my former note (supra, p. IOI) I cannot find that I have been guilty of even " a slight confusion of dates," as Mr. Forbes says (supra, p. I26). On his last visit to Cambridge he told me he had forgotten the name I had before written, and asked me to renew my suggestion. I thank him for the kind terms in which he speaks of me, but I must be allowed to dis claim the opinion "that the Chatham Island form was nearer to Aphanapteryx than the latter was to Erythromachus."

Magdalene College, Cambridge, June ro.

\section{ALFRED NEWTON.}

\section{Linnean Society Procedure.}

AT the anniversary meeting of the Linnean Society complaint was made that the attendances at the evening meetings were greatly falling off, and fellows were urged to remedy this. The bad attendance is, I think, largely attributable to the lamentably unbusinesslike routine into which the Society's proceedings have fallen, and is not likely to be remedied until that is first remedied. Permit me to indicate what appear to me four primary defects in the Society's proceedings.

(I) The actual scientific business of the evening is frequently disposed of in an hour; so that fellows, who attend, sacrifice their evening for very inadequate reward.

(2) In the agenda no intimation is given as to whether the papers to be read will be really reall by their authors, or whether merely a few sentences will be rattled through by the secretary in order that the paper can be marked as "read." It may thus happen that fellows who attend specially to hear some particular paper read and discussed get nothing for their pains. For instance, a short time since, some of us came up specially to hear a paper by Dr. Plowright on the Aecidiomycetes, but instead of being treated to a biological paper, followed by a discussion, all that we heard was a few sentences from the introduction read by the secretary : Naturally this sort of thing militates against regular attendances.

(3) Even when an important paper is intended to be read, it may not be reached at all, or if reached may be hurried over and not discussed for want of time. Why is this? Simply because the Society allows "exhibitions" to be intercalated between the formal business and the papers. These exhibitions are often of much interest, often, again, very trivial, but anyhow are quite secondary in impurtance to the papers, and clearly should be deferred until the papers have been disposed of, instead of taking precedence. These exhibitions are not advertised in the diaries of Societies; and it is rather hard that fellows, who have attended to hear an important paper on some new dis. covery, should go away disıppointed because some inconsiderate visitor possibly is allowed to prose about a trifling exhibition for half an hour!

(4) A very grave defect is the confusion of heterogeneous subjects in one evening. If, for instance, alternate meetings were devoted entirely to botanical and zoological papers respectively, probably the attendances would be increased ; but the botanists cannot be expected to display much interest in a new genus of earthworms, nor the zoologists in a monograph of Dianthus.

If the Council could see their way to adopting these simple reforms that I have suggested, I believe that the attendances would be much increased.

F. H. P. C.

\section{THE GERMAN MATHEMATICAL ASSOCIATION.}

THIS is the Catalogue of the Exhibition that was to have been held last year in the picturesque old town of Nürnberg; but in consequence of the state of health in Germany, the meeting of the German Mathematical Association and the exhibition were postponed; and they are now to be carried out this year at Munich, in the month of September.

The last exhibition of a similar kind was that held in London in 1876 , the catalogue of which shows that a large collection of apparatus, much of it of a great historical interest, was brought together.

1 "Catalogue of Mathematical and Mathematico physical Models, Apparatus, and Instruments." Edited, in conjunction with numerous colleagues, by Walther Dyck. Munich, $\dot{x} 892$.

NO. I 233 , VOL. 48 ]
In the present collection the objccts of historical interest are comparatively few in number; but, on the other hand, the various models and apparatus intended to illustrate mathematical principles and ideas show what great advances have been made in this branch, so. much neglected in our own country.

Prof. Armstrong has recently described in these columns the superiority of the systematic manner in which chemical science is carried out in Germany; and the present Catalogue will show how much we have to. learn in the principles of object teaching and illustration in Mathematics.

The Catalogue is divided into two parts. The first part consists of a collection of short and interesting articles.

I. "Geometrical enumeration of the real roots of algebraical equations," by F. Klein, in connection with. which No. 47, the plaster model of Sylvester's Amphigenous Surface (constructed by Prof. Henrici) for showing the relations for a quintic equation, may be considered.

II. "Equidistant curve-systems on surfaces," by $\mathrm{A}$. Voss.

III. "Elementary discrimination of singularities of algebraical curves," by A Brill; illustrated by instructive diagrams.

IV. "On the constructive postulates of geometry of space, in their relation to the methods of descriptive geometry," by G. Hauck ; an article of great interest to. students of Euclid's axioms, and of their modern developments.

V. "Historical studies on the orgaric description of plane curves, from the earliest times to the end of the eighteenth century," by A. v. Braunmülal ; in this article the mechanical methods of the construction of curves; which are perpetually being re-invented, are traced back to their original sources, with interesting historical references.

VI. "On the methods of theoretical Physics," by L. Boltzmann, is a humorous article, describing the former antiquated methods of teaching Natural Philosophy in Germany, apparently not very different to what many of us remember in this country, until Maxwell's vivifying influence made itself felt.

Prof. Boltzmann gives with wonderful clearness Maxwell's ideas about the use of models in Physics; contrasting the views introduced by him with those held before. This article of Prof. Boltzmann is in course of translation and publication by the Physical Society.

VII. "Mechanical integration," by A. Amsler; this gives a complete account of the theoretical principles which underlie the action of Planimeters ; it is illustrated with carefully-drawn diagrams.

VIII. "Instruments for Harmonic Analysis," by $O$. Henrici.

The Catalogue proper begins with the second part; this again is divided into three sections.

The first section contains instruments relating to Arithmetic, Algebra, Theory of $\mathrm{F}$ unctions, and Integral Calculus, such as Arithmometers, of which the collection and illustrations appear very complete; Galton's Quicunx, illustrating the laws of probability of error; instruments for the solution of equations, Galton's Trace-computer, models of Riemann sheets by Prof. Schwarz, of functions of a complex variable by Prof. Dyck, and a very complete and profusely illustrated collection of Planimeters and Harmonic Analysers of all descriptions. The Rev. F. Bashforth's pioneering description of a Harmonic Analyser, read before the British Association in 1845 , deserves especial attention. The elegant little planimeter of Messrs. Hine and Robertson, of New York, might well find a place in the exhibition. In this instrument the record of area is made by the sidelong movement of a sharp-edged wheel 